\title{
Bond strength repair of a bulk-fill composite using different adhesive systems and resin composites
}

\author{
Resistência de união de reparos de um compósito bullk filll utilizando diferentes sistemas adesivos e \\ resinas compostas
}

Fuerza de adhesión de las reparaciones de un material compuesto de relleno a granel utilizando diferentes sistemas adhesivos y resinas compuestas

\begin{abstract}
In this study evaluated the effect of different adhesive systems and resin composites on the microtensile bond strength of repairs using a bulk-fill composite. Ninety specimens were prepared using a half-hourglass mold of composite Filtek Bulk Fill using a silicone matrix. Specimens were randomly distributed in 9 experimental groups $(\mathrm{n}=10)$ according to adhesive [Universal Single Bond (SBU), Scotchbond Multipurpose Adhesive (SBMP), and Single Bond 2 (SB2)] and resin composite (Filtek Bulk Fill, Aura Bulk Fill, and Filtek Z250). For control group, hourglass specimens were used to measure the ultimate bond strength. Specimens were submitted to thermal cycling (5,000 cycles, 5 and $55^{\circ} \mathrm{C}, 30 \mathrm{~s}$ ) to simulate the aging of restoration and then the repair procedure was performed. After the diamond-tipped surface roughening to be repaired, the adhesive protocol was performed according to group, the specimen was placed in an hourglass-shaped mold and the other half was filled with the repair composite. After 24h, bond strength of specimens was obtained by microtensile using a universal testing machine at a speed of $0.5 \mathrm{~mm} / \mathrm{min}$. Data were statistically analyzed by two-way ANOVA, Tukey's and Dunnett's tests $(\alpha=0.05)$. SBU showed higher bond strength compared to SB2, while SBMP showed intermediate values. However, all experimental groups showed lower bond strength compared to ultimate bond strength. In conclusion, bulk-fill composite repair using universal or conventional solvent-free adhesive improved the adhesion independent of composite tested.
\end{abstract}

Keywords: Adhesiveness; Dentin-bonding agents; Dental restoration repair; Composite resins.

\section{Resumo}

Neste estudo foi avaliado o efeito de diferentes sistemas adesivos e resinas compostas na resistência de união de reparos utilizando um compósito bulk fill. Noventa espécimes do compósito Filtek Bulk Fill foram preparados utilizando uma matriz de silicone de meia ampulheta. Os espécimes foram distribuídos aleatoriamente em 9 grupos experimentais $(\mathrm{n}=10)$ de acordo com adesivo [Single Bond Universal (SBU), Scotchbond Multipurpose Adesivo (SBMP) e Single Bond 2 (SB2)] e compósito (Filtek Bulk Fill, Aura Bulk Fill e Filtek Z250). Para o grupo controle, 
espécimes no formato de ampulheta foram utilizados para mensurar a resistência coesiva do material. Os espécimes foram submetidos à ciclagem térmica $\left(5,000\right.$ ciclos, 5 e $\left.55^{\circ} \mathrm{C}, 30 \mathrm{~s}\right)$ simulando o envelhecimento da restauração e o reparo realizado. Após asperização com ponta diamantada da superfície a ser reparada e realizado o protocolo adesivo, o espécime foi posicionado em uma matriz em formato de ampulheta e a outra metade da matriz foi preenchida com o compósito de reparo. Após 24h, a resistência de união dos espécimes foi obtida por microtração usando uma máquina de ensaio universal sob velocidade de $0,5 \mathrm{~mm} / \mathrm{min}$. Os dados foram estatisticamente analisados pelos testes de ANOVA, Tukey e Dunnett $(\alpha=0,05)$. O SBU apresentou maior resistência de união quando comparado ao SB2, enquanto o SBMP mostrou valores intermediários. Entretanto, todos os grupos experimentais apresentaram valores de resistência de união inferiores à resistência coesiva do grupo controle. O reparo do compósito bulk fill usando o adesivo universal ou convencional livre de solvente mostrou melhor adesão independente do compósito testado.

Palavras-chave: Adesividade; Adesivos dentinários; Reparação de restauração dentária; Resinas compostas.

\section{Resumen}

En este estudio, se evaluó el efecto de diferentes sistemas adhesivos y resinas compuestas sobre la fuerza de adhesión de las reparaciones utilizando un compuesto de relleno a granel. Se prepararon noventa muestras del compuesto Filtek Bulk Fill utilizando una matriz de silicona cada media hora. Las muestras se asignaron aleatoriamente a 9 grupos experimentales $(\mathrm{n}=10)$ según el adhesivo [Single Bond Universal (SBU), Scotchbond Multipurpose Adhesive (SBMP) y Single Bond 2 (SB2)] y el compuesto (Filtek Bulk Fill, Aura Bulk Fill y Filtek Z250). Para el grupo de control, se utilizaron muestras de reloj de arena para medir la fuerza cohesiva del material. Las probetas se sometieron a ciclos térmicos $\left(5.000\right.$ ciclos, 5 y $55^{\circ} \mathrm{C}$, 30s) simulando el envejecimiento de la restauración y la reparación realizada. Después de la asperización con punta de diamante en la superficie a reparar y se realizó el protocolo de adhesivo, la muestra se colocó en una matriz en forma de reloj de arena y la otra mitad de la matriz se rellenó con el composite de reparación. Después de $24 \mathrm{~h}$, se obtuvo la fuerza de adhesión de las probetas mediante el ensayo de microtensión utilizando una máquina de ensayo universal a una velocidad de $0,5 \mathrm{~mm} / \mathrm{min}$. El modo de falla se analizó con una lupa estereoscópica. Los datos se analizaron estadísticamente mediante ANOVA, pruebas de Tukey y Dunnett $(\alpha=0,05)$. SBU mostró una mayor fuerza de adhesión en comparación con SB2, mientras que SBMP mostró valores intermedios. Sin embargo, todos los grupos experimentales mostraron valores de fuerza de adhesión más bajos que la fuerza de cohesión del grupo de control. El modo de falla predominante fue el tipo adhesivo. La reparación del material compuesto de relleno a granel utilizando el adhesivo sin disolvente universal o convencional mostró una mejor adhesión independientemente del compuesto probado.

Palabras clave: Adhesividad; Recubrimientos dentinarios; Reparación de restauración dental; Resinas compuestas.

\section{Introduction}

Adhesive Dentistry enables minimally invasive restorative procedures, restoring the shape, function, and esthetic of teeth; replacing the loss of dental structure, either by carious processes or trauma, using direct and indirect restorations. Thus, the clinical use of resin composite as a restorative material has increased considerably in recent years because of the excellent esthetic properties and simplified adhesion procedures, especially in direct restorations (Duran et al., 2015; Fornazari et al., 2017; Kiomarsi et al., 2017; De Medeiros et al., 2019).

However, resin composites are subject to occurrence of failures that may lead to clinical failure of adhesive restorations. Among the most common problems are fractures, margin staining, color change, deficiency in restoration anatomy, recurrent caries, and postoperative sensitivity (Duran et al., 2015; Kiomarsi et al., 2017).

The difficulty of differentiating between restoration margins and cavity walls, as well as the need to remove previously conditioned enamel and dentin, in order to make a new adhesive restoration (Shahdad \& Kennedy, 1998), may result in occurrence of larger and larger cavities at time of deficient restorations replacement (Duran et al., 2015; Kiomarsi et al., 2017; Cueva-Suárez et al., 2020). Thus, resin composites have been increasingly used for dental restorations due to their favorable features by requiring less clinical time to perform, satisfactory cost-benefit ratio, acceptable esthetic and it represents a more conservative procedure in some situations (Cueva-Suárez et al., 2020).

Success in repair procedures depends in obtaining an adequate adhesive interface between the aged and new composite. Several studies (Baur \& Ilie, 2013; Lima et al., 2014; Baena et al., 2015; Ahmadizenouz et al., 2016; Lima et al., 2016; Fornazari et al., 2017) have been shown that combination between the treatment of surface to be repaired and the use of 
adhesive systems can increase the bond strength between resin composites. Furthermore, the repair of composite restorations could be performed regardless of composite type and adhesive technique employed (Turner \& Meiers. 1993).

In an attempt to speed up the restoration process, bulk-fill composites of low polymerization allow to build increment of 4-5 $\mathrm{mm}$ of thickness and it may be polymerized in one step, reducing the time that would be necessary in incremental technique (Ilie et al., 2013; Ayar et al., 2019; De Medeiros et al., 2019; Rocha et al., 2020). Clinically, large and deep cavities could be restored more easily and quickly with the use of these materials (Ilie et al., 2014; Carvalho et al., 2020). In addition, universal or multimode adhesive systems that can be used under any application technique and on any surface, some including the bifunctional silane molecule, they could promote adequate adhesion between the aged restoration and composite used in repair procedure (Cura et al., 2016; De Medeiros et al., 2019).

However, after performing the restoration, there is no way to differentiate with which resin composite it was made, leading the clinician to try a simpler, faster, and more conservative intervention such as repair, in cases where it is necessary. Therefore, in this study was evaluated the effect of different adhesive systems and resin composites on bond strength of repairs using bulk-fill composite. The null hypotheses were that there would be no difference on bond strength among the (I) adhesive systems and (II) resin composites used in repair procedure.

\section{Methodology}

\section{Experimental design}

The experimental design in this study was two factors randomized complete block arrangement. The factors considered were adhesive systems in three levels (Single Bond Universal - SBU, Scotchbond Mutipurpose Adhesive - SBMP, and Single Bond 2 - SB2) and resin composites in three levels (Filtek Z250, Aura Bulk Fill, and Filtek Bulk Fill).

\section{Specimen preparation}

For this study, 90 blocks of a bulk-fill composite (Filtek Bulk Fill - B1 shade; 3M ESPE, St. Paul, MN, USA) were carried out using silicone matrix. The half-hourglass matrix was filled with the resin composite, and then covered with a polyester strip and a glass slide. To compact the material and prevent bubble formation, the glass slide was gently pressed to remove excess material. Resin composite was light cured for $20 \mathrm{~s}$, using a polywave LED (light emitting diode) Bluephase $\mathrm{N}$ (Ivoclar Vivadent, Schaan, Liechtenstein) at irradiance of $1,200 \mathrm{~mW} / \mathrm{cm}^{2}$, monitored by a radiometer (model L.E.D.; Demetron/Kerr, Danbury, CT, USA).

After $24 \mathrm{~h}$, the specimens were submitted to thermal cycling (MSCT-3; Elquip, São Carlos, SP, Brazil) in distilled water $\left(5,000\right.$ cycles, 5 and $55^{\circ} \mathrm{C}, 30 \mathrm{~s}$ bath at each temperature) for aging simulation of restoration. Then, specimens were randomly distributed into nine experimental groups $(n=10)$, according to adhesive system and resin composite for repair. Control group was obtained by making the specimen in hourglass format for measurement of the ultimate bond strength of restorative material.

Prior to repair, the surface treatment was performed using a diamond tip \#3098 (KG Sorensen, Barueri, SP, Brazil) at a constant high speed under refrigeration, only once and in a single direction, covering the whole interface area (Ahmadizenouz et al., 2016). Then, the surface was washed, dried for $15 \mathrm{~s}$, and the adhesive system was applied according to protocols: (A) SBMP (3M ESPE, St. Paul, MN, USA) - conditioning with 35\% phosphoric acid (Ultra-Etch; Ultradent Products Inc., South Jordan, UT, USA) for $15 \mathrm{~s}$, washing, and drying. Then a layer of adhesive was applied using microapplicator and light cured for $10 \mathrm{~s}$; (B) SB2 (3M ESPE) - acid conditioning for $15 \mathrm{~s}$, washing, and drying; followed by application of two layers of adhesive using disposable micro-applicator brush, drying for $5 \mathrm{~s}$, and light curing for $10 \mathrm{~s}$; and (C) SBU (3M ESPE) - surface conditioning using 35\% phosphoric acid for $15 \mathrm{~s}$, washing, and drying. Application of two-layers 
adhesive, drying for $5 \mathrm{~s}$, followed by light curing for $10 \mathrm{~s}$.

A similar matrix was used for repair procedure, but hourglass-shaped. After surface asperization to be repaired and adhesive protocol, the restoration was placed in matrix and the other half was filled with composite that was performed the repair: Filtek Bulk Fill (A2 shade - 3M ESPE), Aura Bulk Fill (Universal shade - SDI Limited, Bayswater, VIC, Australia), and Filtek Z250 (A2 shade - 3M ESPE). The repair composite was used in different color of restoration in order to facilitate the evaluation of failure mode.

\section{Bond strength}

Firstly, adhesive interface area was measured using a digital caliper (Mitutoyo Sul Americana, Suzano, SP, Brazil), then specimens were individually fixed in a device of universal testing machine (EMIC 23-2S; Instron, São José dos Pinhais, PR, Brazil) with cyanoacrylate-base glue. The adhesion area was positioned perpendicularly to long axis of tensile force. Tests were performed at a constant velocity of $0.5 \mathrm{~mm} / \mathrm{min}$ until rupture. Microtensile bond strength values were measured in Newtons $(\mathrm{N})$ and transformed into MegaPascal $(\mathrm{MPa})$, by dividing the force $(\mathrm{N})$ by adhesive area $\left(\mathrm{mm}^{2}\right)$.

\section{Failure mode}

After the microtensile test, the fractured interfaces of each sample were evaluated in a stereomicroscope (45x, Meiji 2000; Meiji Techno, Saitama, Japan) to determine the failure mode of each specimen. Fracture pattern was classified according to predominant failure mode: (a) adhesive failure at restoration/repair interface, (b) cohesive failure in composite of restoration, (c) cohesive failure in composite of repair, or (d) mixed failure (combination of failure modes) (Fornazari et al., 2017).

\section{Statistical analysis}

The sample size was determined by preliminary tests comparing with previous values published (Lima et al., 2016), in which that number of specimens yielded adequate power at $\alpha=0.05$, this sample size reached a power of 1 for detecting statistically significant differences. Data normality and homogeneity were verified by Kolmogorov-Smirnov and Levene tests, respectively. Data were analyzed by two-way analysis of variance (ANOVA) and Tukey's post hoc test $(\alpha=0.05)$. For comparison of experimental groups with control group, the Dunnett's test was used at significance level of 5\% (SPSS Version 20, IBM Corp., Armonk, NY, USA).

\section{Results}

A significant difference on bond strength was observed only for adhesive system factor $(p=0.03)$. There was no significant difference for resin composite and factor interactions ( $p>0.05)$. SBU showed higher bond strength compared to SB2, while SBMP showed intermediate values and without significant difference compared to SBU and SB2. Meanwhile, all experimental groups showed lower ultimate bond strength values compared to control group (Table 1). 
Table 1. Bond strength (MPa) means (standard deviation) according adhesive system and composite resin used for repair.

\begin{tabular}{ccccc}
\hline \multirow{2}{*}{ Adhesive system } & \multicolumn{3}{c}{ Composite resin } & \multirow{2}{*}{ Pooled data } \\
\cline { 2 - 4 } & Filtek Z250 & Aura Bulk Fill & Filtek Bulk Fill & \\
\hline SBU & $27.82(7.29)^{*}$ & $28.47(5.34)^{*}$ & $28.80(7.27)^{*}$ & $28.36(6.47) \mathrm{a}$ \\
SBMP & $26.44(5.98)^{*}$ & $25.87(5.21)^{*}$ & $26.78(4.67)^{*}$ & $27.03(6.13) \mathrm{ab}$ \\
SB2 & $23.88(6.16)^{*}$ & $22.85(5.37)^{*}$ & $23.08(5.04)^{*}$ & $23.27(5.37) \mathrm{b}$ \\
\hline
\end{tabular}

Control group $46.86(6.78)$

SBU: Universal Single Bond; SBMP: Scotchbond Multipurpose Adhesive; SB2: Single Bond 2. Different lowercase letters indicate a significant difference between the adhesive systems, regardless of composite resin $(\mathrm{p}<0.05)$. *It differs from control group by Dunnett's test $(5 \%)$. Source: Authors.

The distribution of failure modes occurred according to adhesive and composite used in repair procedure (Figure 1). The predominant failure mode for all experimental groups was adhesive type, especially when the repair was performed with SB2.

Figure 1. Failure mode (\%) according to adhesive system and composite resin used in repair procedure. SBU: Universal Single Bond; SBMP: Scotchbond Multipurpose Adhesive; SB2: Single Bond 2.

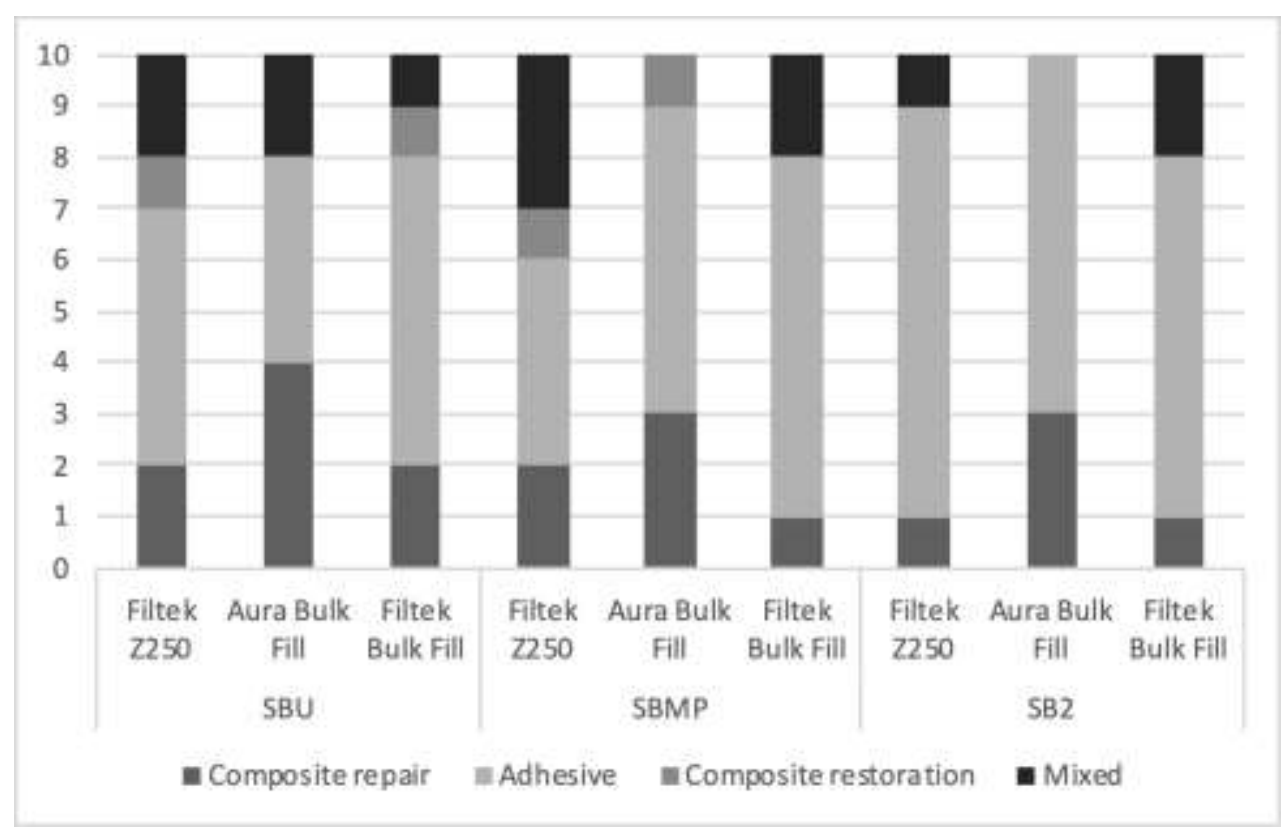

Source: Authors.

\section{Discussion}

Success in repair procedures depends on obtaining an adequate adhesive interface between the aged and new resin composite. Several studies (Baur \& Ilie, 2013; Lima et al., 2014; Baena et al., 2015; Ahmadizenouz et al., 2016; Lima et al., 2016; Fornazari et al., 2017) showed that the combination between the surface treatment to be repaired and the use of adhesive systems increase the bond strength between the composites. In this study, it was simulated restorations performed using a bulkfill resin composite and evaluated the bond strength of repairs performed with different adhesive systems and resin composites.

An important step for success of repair procedure is the surface asperization, that has the function of increasing the surface roughness and consequently increasing the bond strength by mechanical adhesion (Brunton et al., 2017). Some 
methods have been evaluated for this purpose, such as aluminum oxide blasting, diamond tip asperization, laser pretreatment, hydrofluoric and phosphoric acid application, among others (Duran et al., 2015; Brunton et al., 2017; De Jesus et al., 2017; Fornazari et al., 2017; Ghavam et al., 2018; Ayar et al., 2019). Microporosities creation using diamond-tip in high rotation propitiates the micro-retention of resin-based materials, showing effectiveness in adhesion increase of way practical and accessible for clinicians (De Jesus et al., 2017; Ghavam et al., 2018), thus this method was selected in the present study for roughening of aged composite.

After surface treatment to increase the roughness, the silane coupling agent has been usually used as bonding agent, in order to improve the adhesion between the filler particles and organic matrix of aged and new resin composite, because it is a bifunctional molecule capable of to bind with carbon double bonds of organic matrix by non-hydrolyzable functional group and hydroxyl groups of inorganic phase by hydrolyzable alkoxy groups (Fornazari et al., 2017). However, the benefit of using silane is controversial, as some studies (Ferracane, 2011; Tantbirojn et al., 2015; Fornazari et al., 2017; Cuevas-Suárez et al., 2020) reported the increase on bond strength of composite repairs, while others (Cho et al., 2013; Lima et al., 2014) showed no difference in use or not of this bifunctional coupling agent.

In this way, isolated silane application was not tested, it was assessed a universal adhesive containing this bifunctional molecule and that can be used under any adhesive technique and on any surface (Cura et al., 2016), which could promote adequate adhesion between restoration and composite used to perform the repair. As reported by previous studies (Fornazari et al., 2017; Çakir et al., 2018) the silane-containing universal adhesive alone was as effective as any combination of silane and adhesive, particularly when applied to abraded surfaces, and requiring fewer steps during adhesive protocol, corroborating with our study in which the adhesive system containing silane showed higher bond strength.

The conventional solvent-free adhesive used in this study also resulted in adequate bond strength values, promoting similar adhesion to universal adhesive evaluated. Probably the absence of solvents in adhesive could explain this finding, since solvent-free adhesives have superior mechanical properties when compared to solvated adhesives, due to formation of a polymer with higher crosslink density (Gaglianone et al., 2012). In addition, the use of more hydrophobic intermediate resinbased materials promotes higher bonding stability (Ferracane, 2011). Conventional solvated adhesive showed lower bond strength compared to universal adhesive, possibly by reduction of its mechanical properties due to presence of solvents that result in a polymer with more linear bonds (Gaglianone et al., 2012). Thus, adhesive systems showed different behavior on bond strength of repairs to aged bulk-fill composite, thus the first null hypothesis was not accepted.

Bulk-fill composites were modified in their composition, which resulted in increased translucency, allowing greater penetration of light in deeper layers of restoration, more reactive photoinitiators, and incorporation of different filler particles, such as pre-polymers and glass fibers (Benetti et al., 2015; Fronza et al., 2015). However, monomeric composition is based on dimethacrylates as in conventional resin composites, which probably resulted in no difference on bond strength among composites tested. Thus, the second null hypothesis was accepted.

In general, the predominant failure mode for all experimental groups was adhesive type (60\%), especially for group in which the conventional solvated adhesive system was used, which presented the lowest bond strength values and lower mechanical properties (Gaglianone et al., 2012). Failure of composite restoration was the less frequent type (4.45\%), and this fracture pattern was not found when the repair was performed using adhesive containing solvent. Failure in composite repair and mixed type were observed in 21.11 and $14.44 \%$ of cases, respectively.

Therefore, the repair of composite restorations seems to be a viable alternative to replacement, it considered a minimally invasive procedure, since it preserves dental structure, in addition to requiring less time and less cost to perform (Brunton et al., 2017), showing success after 7 years of clinical use (Demarco et al., 2012). However, all experimental groups presented lower bond strength to the ultimate bond strength of composite in which the restoration was made (control group). In 
this way, other surface treatments should be evaluated to verify the improvement in effectiveness of repair procedure of adhesive dental restorations.

\section{Conclusion}

According to results, it can be concluded that the universal and solvent-free conventional adhesive systems are preferable to repair procedure because they promoted higher bond strength and bulk-fill composite can be repaired adequately using bulk-fill and conventional resin composites.

\section{Acknowledgments}

This research was supported by Institutional Scientific Initiation Scholarship Program (PIBIC, grant \#118152/2016-5) of National Council for Scientific and Technological Development (Conselho Nacional de Desenvolvimento Científico e Tecnológico - CNPq) and University of Western São Paulo (Unoeste grant \#3170). The authors declare any conflicts of interest.

\section{References}

Ahmadizenouz, G., Esmaeili, B., Tagvaei, A., Jamali, Z., Jafari, T., Daneshvar, F. A., \& Khafri, S. (2016) Effect of different surface treatments on the shear bond strength of nanofilled composite repairs. J Dent Res Dent Clin Dent Prospects, 10, 9-16.

Ayar, M. K., Guven, M. E., Burduroglu, H. D., \& Erdemir, F. (2019) Repair of aged bulk-fill composite with posterior composite: Effect of different surface treatments. J Esthet Restor Dent, 31, 246-252.

Baena, E., Vignolo, V., Fuentes, M. V., \& Ceballos, L. (2015) Influence of repair procedure on composite-to-composite microtensile bond strength. Am J Dent, 28, 255-260.

Baur, V., \& Ilie, N. (2013) Repair of dental resin-based composites. Clin Oral Investig, 17, 601-608.

Benetti, A. R., Havndrup-Pedersen, C., Honoré, D., Pedersen, M. K., \& Pallesen, U. (2015) Bulk-fill resin composites: polymerization contraction, depth of cure, and gap formation. Oper Dent, 40, 190-200.

Brunton, P. A., Ghazali, A., Tarif, Z. H., Loch, C., Lynch, C., Wilson, N., \& Brum, I. R. (2017) Repair vs replacement of direct composite restorations: a survey of teaching and operative techniques in Oceania. J Dent, 59, 62-67.

Çakir, N. N., Demirbuga, S., Balkaya, H., \& Karadaş, M. (2018) Bonding performance of universal adhesives on composite repairs, with or without silane application. J Conserv Dent, 21, 263-268.

Carvalho, H. C., Geha, O., Zanin, G. T., Reis, M. F. B., Guiraldo, R. D., Matos, A. N. F., Aranha, A. M. F., \& Berger, S. B. (2020) Effect of bleaching agents on mechanical properties of bulk fill and conventional composites. Res, Soc Dev, 9, e918998279.

Cho, S. D., Rajitrangson, P., Matis, B. A., \& Platt, J. A. (2013) Effect of Er,Cr:YSGG laser, air abrasion, and silane application on repaired shear bond strength of composites. Oper Dent, 38, E1-9.

Cuevas-Suárez, C. E., Nakanishi, L., Isolan, C. P., Ribeiro, J. S., Moreira, A. G., \& Piva, E. (2020) Repair bond strength of bulk-fill resin composite: Effect of different adhesive protocols. Dent Mater J, 39, 236-241.

Cura, M., González-González, I., Fuentes, V., \& Ceballos, L. (2016) Effect of surface treatment and aging on bond strength of composite resin onlays. J Prosthet Dent, 116, 389-396.

De Jesus Tavarez, R. R., Almeida Júnior, L. J., Guará, T. C., Ribeiro, I. S., Maia Filho, E. M., \& Firoozmand, L. M. (2017) Shear bond strength of different surface treatments in bulk fill, microhybrid, and nanoparticle repair resins. Clin Cosmet Investig Dent, 9, 61-66.

De Medeiros, T. C., De Lima, M. R., Bessa, S. C., De Araújo, D. F., \& Galvão, M. R. (2019) Repair bond strength of bulk fill composites after different adhesion protocols. J Clin Exp Dent, 11, e1000-1005.

Demarco, F. F., Corrêa, M. B., Cenci, M. S., Moraes, R. R., \& Opdam, N. J. (2012) Longevity of posterior composite restorations: not only a matter of materials. Dent Mater, 28, 87-101.

Duran, İ., Ural, Ç., Yilmaz, B., \& Tatar, N. (2015) Effects of Er:YAG laser pretreatment with different energy levels on bond strength of repairing composite materials. Photomed Laser Surg, 33, 320-325.

Ferracane, J. L. (2011) Resin composite - state of the art. Dent Mater, 27, 29-38. 
Research, Society and Development, v. 10, n. 5, e31410514951, 2021

(CC BY 4.0) | ISSN 2525-3409 | DOI: http://dx.doi.org/10.33448/rsd-v10i5.14951

Fornazari, I. A., Wille, I., Meda, E. M., Brum, R. T., \& Souza, E. M. (2017) Effect of surface treatment, silane, and universal adhesive on microshear bond strength of nanofilled composite repairs. Oper Dent, $42,367-374$.

Fronza, B. M., Rueggeberg, F. A., Braga, R. R., Mogilevych, B., Soares, L. E., Martin, A. A., Ambrosano, G., \& Giannini, M. (2015) Monomer conversion, microhardness, internal marginal adaptation, and shrinkage stress of bulk-fill resin composites. Dent Mater, 31, 1542-1551.

Gaglianone, L. A., Lima, A. F., Gonçalves, L. S., Cavalcanti, A. N., Aguiar, F. H., \& Marchi, G. M. (2012) Mechanical properties and degree of conversion of etch-and-rinse and self-etch adhesive systems cured by a quartz tungsten halogen lamp and a light-emitting diode. J Mech Behav Biomed Mater, 12, 139-143.

Ghavam, M., Naeemi, M., Hashemikamangar, S. S., Ebrahimi, H., \& Kharazifard, M. J. (2018) Repair bond strength of composite: Effect of surface treatment and type of composite. J Clin Exp Dent, 10, e520-527.

Ilie, N., Bucuta, S., \& Draenert, M. (2013) Bulk-fill resin-based composites: an in vitro assessment of their mechanical performance. Oper Dent, 38, 618-625.

Ilie, N., Schöner, C., Bücher, K., \& Hickel, R. (2014) An in-vitro assessment of the shear bond strength of bulk-fill resin composites to permanent and deciduous teeth. J Dent, 42, 850-855.

Kiomarsi, N., Saburian, P., Chiniforush, N., Karazifard, M. J., \& Hashemikamangar, S. S. (2017) Effect of thermocycling and surface treatment on repair bond strength of composite. J Clin Exp Dent, 9, e945-951.

Lima, A. F., Ferreira, S. F., Catelan, A., Palialol, A. R., Gonçalves, L. S., Aguiar, F. H., \& Marchi, M. G. (2014) The effect of surface treatment and bonding procedures on the bond strength of silorane composite repairs. Acta Odontol Scand, 72, 71-75.

Lima, A. F., Leite, T. V., Palialol, A. M., Catelan, A, Aguiar, F. H. B., Marchi, G. M., Yuzbasiogluc, E., \& Özcan, M. (2016) Effect of surface conditioning methods, adhesive systems and resin composite on repair strength of dimethacrylate and silorane resin composites. J Adhes Sci Technol, 30, $2736-2744$.

Rocha, M. I. S., Santos-Filho, P. C. F., Dietrich, L., Reis, T. A., Magalhaes, M. A., \& Martins, V. M. (2020) Depth of cure of the bulk fill resin composite from different light source. Res Soc Dev, 9, e7509109190.

Shahdad, S. A., \& Kennedy, J. G. (1998) Bond strength of repaired anterior composite resins: an in vitro study. J Dent, 26, 685-694.

Tantbirojn, D., Fernando, C., \& Versluis, A. (2015) Failure Strengths of composite additions and repairs. Oper Dent, 40, 364-371.

Turner, C. W., \& Meiers, J. C. (1993) Repair of an aged, contaminated indirect composite resin with a direct, visible-light-cured composite resin. Oper Dent, $18,187-194$. 